\title{
IF THE MIND KNOWS, THE EYES CAN SEE - THE FIRST CASE OF NEONATAL LISTEROSIS REPORTED FROM EASTERN INDIA
}

Raja Ray, Jayanta Bikash Dey, Indrani Bhattacharyya, Sanat Kumar Ghosh, Soumitra Roy
1. Professor, Department of Microbiology, West Bengal Medical Education Service, Bankura Sammilani Medical College, Bankura.
2. Associate Professor, Department of Microbiology, Bankura Sammilani Medical College, Bankura.
3. Assistant Professor, Department of Microbiology, Bankura Sammilani Medical College, Bankura.
4. Demonstrator, Department of Microbiology, Bankura Sammilani Medical College, Bankura.
5. Medical Technologist, Department of Microbiology, Bankura Sammilani Medical College, Bankura.

\section{CORRESPONDING AUTHOR}

Prof Raja Ray,

A/11, Survey Park.

Kolkata - 75

E-mail: rjrm1175@gmail.com,

Ph: 00919433323454

\begin{abstract}
A three day old baby delivered at B. S. Medical College Hospital, Bankura developed features of neonatal septicaemia two days after normal delivery. Patient's blood culture sample was processed in BacT/Alert 3D Automated blood culture system. Positive growth signal was obtained at $48 \mathrm{hrs}$. Subculture on solid non-selective and selective media, morphological studies including typical motilities and standard recommended bio-chemical tests revealed the isolate to be Listeria monocytogenes. Antibiogram studies further corroborated the identity of the isolate. This case report underlines the importance of Automated blood culture detection system in the identification of fastidious but clinically dangerous pathogens. This is most probably the first report of neonatal septicemia due to Listeria monocytogenes from eastern India.
\end{abstract}

KEY WORDS: Listeria monocytogenes, Neonatal Septicemia, Automated Blood Culture System

INTRODUCTION: Listeria monocytogenes is a relatively rare aerobic, gram positive nonsporing bacillus causing human infection most commonly in neonates. It can survive in a wide range of environmental conditions. The temperature tolerance of this bacteria ranges from $4^{\circ} \mathrm{C}$ to $37^{\circ} \mathrm{C}$. It can withstand high salt concentration and low $\mathrm{pH}^{1}$. These properties indicate that they can overcome food preservation procedures and safety barriers, thus becoming an important and highly fatal food borne pathogen ${ }^{2}$. It has been found that $20-30 \%$ of clinical infections can result in death ${ }^{3}$. The first case of human listeriosis was reported in March, 1978 from South Africa ${ }^{4}$.

CASE HISTORY: This case report is being made from the Department of Microbiology, Bankura Sammilani Medical College, Bankura which is one of the well known government run teaching hospitals in West Bengal and has a well equipped Microbiology laboratory. The patient was a three day old baby whose birth weight was $2.5 \mathrm{~kg}$. Delivery was institutional (in this hospital) and full term. Two days after normal vaginal delivery the patient presented with frequent episodes of convulsions. Each episode lasted for 5-10 minutes. The baby was immediately transferred to the SNCU (Sick New Born Unit) of this hospital. Examination revealed: Anaemia, Jaundice, Oedema \& Clubbing - Nil, Chest- Clear, Heart sounds - S1, S2 audible, Abdomen- Soft, Liver \& Spleen- Not palpable. Patient was diagnosed provisionally as Neonatal Septicaemia.CBC 
revealed Neutrophil 7,000/cc, ESR 30 mm first hour, Platelet count $2,10,000 / c c .0 .5$ cc of blood was sent for culture in BacT/ALERT 3D Select system in appropriate culture bottle. CSF sample could not be collected as the baby was suffering from repeated convulsions. Treatment was started with Inj. Cefotaxime \& Amikacin, Inj. Gardenal, Inj. Vit K, I.V fluid with Isolyte P.

Culture media provided in BacT/Alert 3D Select blood culture bottle contains Soyabean Caesin Digest, Sodium Polyanethol Sulfonate, Pyridoxine, Menadione, Hemin, L-Cysteine Broth with Brain Heart infusion. The culture bottle was incubated at $37^{\circ} \mathrm{C}$ in an atmosphere of $\mathrm{CO}_{2}$ in oxygen and nitrogen under vacuum in the above system and positive growth signal was obtained in 48 hours. Direct smear was made from Blood Culture bottle and stained by Gram stain. Smear showed small non-sporing gram positive bacilli. Arrangement was mostly single, few pairs, few short chains, V and L shaped diphtheroid arrangements were found also. There were no granules. Typical pallisades were not seen. Subculture was made in 5\% Sheep Blood Agar, Nutrient Agar \& MacConkey Agar. The plates were incubated at $37^{\circ} \mathrm{C}$ for $24 \mathrm{hrs}$.

CULTURE FINDINGS: After $24 \mathrm{hrs}$ in 5\% Sheep Blood Agar, small zone of haemolysis was seen around the discrete colonies. In Nutrient Agar, small translucent colonies and in MacConkey agar no growth occurred. Growth on selective medium, Palcam Listeria Selective Supplement Agar was also checked. Smear was made from the colonies on Blood Agar and Nutrient Agar and Listeria selective medium and stained with Gram stain. Gram positive non-sporing bacilli having the previous characteristics were detected. One inoculated peptone water tube was incubated for $2 \mathrm{hrs}$ at $37^{\circ} \mathrm{C}$ and another was incubated at $24^{\circ} \mathrm{C}$ for $2 \mathrm{hrs}$. Hanging drop preparations were made from both tubes. Most of the bacilli incubated at $37^{\circ} \mathrm{C}$ were non-motile and most bacilli incubated at $24^{\circ} \mathrm{C}$ showed typical tumbling motility. Biochemical reactions: Catalase test positive, Oxidase test - Negative, Glucose \& Maltose fermented with production of acid only and aesculin hydrolysis were positive. MR and VP - Positive, CAMP Reaction was also positive. ${ }^{5}$

FINAL DIAGNOSIS: So the patient, a new born baby following vaginal delivery developed neonatal septicemia with convulsion whose aerobic blood culture yielded positive result showing Gram positive bacilli with characteristic arrangement. This is followed by the culture finding of growth in 5\% Sheep Blood Agar with haemolysis \& growth in Nutrient Agar, but no growth in Mac Conkey Agar. Tumbling motility at $24^{\circ} \mathrm{C}$ and no motility at $37^{\circ} \mathrm{C}$ with the characteristic biochemical test findings clearly pointing towards a diagnosis of Listeria monocytogenes. Antibiotic susceptibility testing was done by Kirby-Bauer disc diffusion method. The organism was sensitive to Ampicillin, Co-trimoxazole and Gentamycin and it was resistant to Cephalosporin and Fluoroquinolones.

Listeriosis in man may show diverse clinical features. Meningitis is a very important outcome of L. monocytogenes infection in newborn, elderly and immunocompromised patients. Asymptomatic infection of the female reproductive canal may cause intranatal infection of the newborn, as was most probably the case in this patient. The patient was discharged early after delivery.

As neonatal listeriosis has never been reported from this region of West Bengal, this case definitely needs to be reported. Scanning of scientific literature revealed four previously reported cases of neonatal listeriosis from India (Mokta KK et al 20166, Gogate AA et al 19817, Khan Sadia et al 20118, and Gupta Ritu et al 19979'9), but none of these cases were from eastern India. This should be an eye-opener to clinicians who need to be more vigilant. This case also authenticates the great diagnostic sensitivity of automated blood culture systems in the detection of fastidious blood pathogens.

Journal of Evolution of Medical and Dental Sciences/Volume1/Issue5/November-2012Page-762 


\section{BIBLIOGRAPHY:}

1. Human Listeriosis caused by Listeria Ivanovi. Emerg Inf Diseases.2012; 168(1): 16-18.

2. Bortollusi R, Mailman TM: Listerosis, in Infectious Disease of the Fetus and Newborn Infant. $6^{\text {th }}$ ed, S Remington et al. Philadelphia.2005 .Elsevier Saunders : 465

3. Kraft Jurgen,Goebel Werner et al.Listeria, Pathogenesis and Molecular Virulence Determinants. Clinical Microbiology ReviewJuly,2001; 14(3): 584-640.

4. Adams Hilde,Toxopeus H. Neonatal Listeria monocytogenes Meningitis. South African Medical Journal.March, 1978; 53: 463 .

5. Mahy Brian W J,Murray Patricket al..Topley \& Wilson's Microbiology \& Microbial Infections.

John Wiley \& Sons,Inc.,UK,10 th Edition. 2005. Vol 2: 959-961.

6. Mokta KK, Kanga AK, Kaushal RK. Neonatal listerosis : a case report from Sub-Himalayas. .Indian Journal of Medical Microbiology .October 2010; Vol 28. Issue 4: 385.

7. Gogate AA, Deodha LP. Meningitis due to Listeria monocytogenes Journal of Post Graduate Medicine. 1981. Vol 27. Issue $4: 240-2$

8. Khan Sadia, Sujatha S, Harish B N, Praharaj I, Parija S.C. Neonatal meningitis due to Listeria monocytogenes : A case report from Southern India.Journal of Clinical and Diagnostic Research .2011 June. 5(3): 608-609

9. Ramachandran V.G, Gupta Piyush.Gupta Ritu Listerosis : An Opportunistic Infection. Indian Pediactrics .August 1997;34:732-734 